\title{
A produção de uma memória discursiva na série de reportagens: "Joga que nem mulher"
}

Maria Simone Vione Schwengber

Doutora em Educação, professora do Programa de Pós-Graduação em Educação nas Ciências - UNIJUÍ.

E-mail: simone@unijui.edu.br

Caterine de Moura Brachtvogel

Professora de Educação Física, mestra em Educação nas Ciências e doutoranda em Educação nas Ciências da UNIJUÍ

E-mail: cati-mb@hotmail.com

Rodrigo Saballa de Carvalho

Professor do Programa de Pós-Graduação em Educação da Universidade Federal do Rio Grande do Sul (PPGEDU/UFRGS) e professor do Curso de Pedagogia da Faculdade de Educação da UFRGS no Departamento de Estudos Especializados (DEE).

E-mail: rsaballa@terra.com.br

Resumo: $\mathrm{O}$ artigo, a partir das contribuições do pensamento de Michel Foucault, assim como dos estudos de gênero, analisa a produção de uma memória discursiva na série de reportagens "Joga que nem mulher" veiculada pela RBS TV. Metodologicamente, trata-se de uma análise do discurso, na qual se questionam os modos como a produção discursiva enunciada na série oportuniza rearranjos das posições das mulheres nos esportes. Através das análises, destaca-se que o enunciado reitor "Joga que nem mulher" opera como memória de combate, contrapondo-se à expressão "Joga que nem homem", flexibilizando a ação de jogar e sinalizando que jogar também é atividade feminina. Desse modo, verifica-se a importância do enunciado reitor veiculado pela série, já que provoca alterações nos discursos acerca das mulheres nos esportes, contribuindo com a difusão de outros modos de enunciação.

Palavras-chave: gênero; esportes; mulheres; mídias digitais; discurso.
Abstract: Our article analyzes the production of a discursive memory in the series of reports "Play like a woman", broadcast on RBS TV, based on the contributions of Michel Foucault and Gender Studies. Methodologically, we used discourse analysis, questioning the ways in which the discursive production enunciated in the series enables rearrangements of women's positions in sports. The analysis emphasizes that the governing statement "Play like a woman" operates as a combat memory, opposing the expression "Play like a man", making the action of playing more flexible and signaling that playing is also a female activity. Thus, the importance of the governing statement conveyed by the series is verified, since it causes changes in the discourses about women in sports, contributing to the diffusion of other modes of enunciation.

Keywords: gender; sports; women; digital media; discourse.
Recebido: 09/08/2019

Aprovado: $23 / 04 / 2020$ 
1. FOUCAULT, Michel. Arqueologia do saber. 7a. ed. Rio de Janeiro: Forense Universitária, 2008

2. Ibidem.

3. FOUCAULT, Michel. A ordem do discurso. 5 a ed. São Paulo: Edições Loyola, 1996.

4. PÚBLICO feminino é alvo de nova plataforma de conteúdo da ESPN. Portal Imprensa, São Paulo, [2018]. Disponível em: http://www. portalimprensa.com.br/ mulheresqueinspiram/materia_21.asp. Acesso em 10 mar. 2019

5. FOUCAULT, 1996.

6. Ibidem.

7. Público feminino..., [2018].

8. A COPA do mundo de futebol masculino de 2018 foi das mulheres. Zero Hora, Porto Alegre, 18 jul. 2018, p. 22-23.

9. Ibidem, p. 23

\section{MULHERES E ESPORTES: POR OUTRAS MOVIMENTAÇÕES DISCURSIVAS}

Este artigo tem como foco a análise das produções discursivas emergentes do enunciado reitor "Joga que nem mulher" de uma série de reportagens veiculada pelo Globo Esporte da RBS TV (RS). Compreendemos o enunciado reitor ${ }^{1}$ como um acontecimento discursivo que, pela sua reiteração (e posição), colabora com a produção de uma memória discursiva. Com base na análise da série de reportagens, discutimos a emergência de uma memória discursiva que indica um processo de ressignificação das posições das mulheres nas práticas esportivas. A partir de uma problemática do tempo presente, que se refere aos modos como as mulheres têm sido posicionadas em um artefato da mídia que as enuncia como jogadoras, propomos, no decorrer do artigo, o exercício de análise das condições de emergência ${ }^{2}$ de tal modo de enunciação. Entendemos que, para apreender os acontecimentos discursivos em suas singularidades e histórias, torna-se necessário evidenciar os modos como as enunciações foram produzidas no decorrer do tempo ${ }^{3}$.

Contemporaneamente, deparamo-nos cada vez mais com enunciados como estes nos espaços esportivos: "Mulher não entende de futebol"; "Ei, bandeirinha, vai lavar louça”; "Teu lugar é em casa”; "Gostosa, gostosa”. Afinal, ainda hoje, os esportes são entendidos, por muitas pessoas, como atividades masculinas; "Ledo engano! Há em curso uma ascensão das mulheres nos campos, quadras e ginásios, seja nas arquibancadas, ruas, parques, clubes, nas pistas, no interesse por programas esportivos brasileiros"4.

A recorrência de enunciados diz respeito àquilo que se separa e se elege, dentro de uma formação específica, e que se legitima ao produzir sentidos e significações, desencadeando uma memória discursiva ${ }^{5}$. Por essa razão, Foucault ${ }^{6}$ sugere proceder a um levantamento da "memória" dos enunciados, acompanhá-los como irrupção, como descontinuidade e como ação. Desafiados por esses pressupostos, tomamos o enunciado "ledo engano, as mulheres estão entrando nos esportes" para evidenciar e problematizar os modos como tal enunciado produz uma caracterização semântica ao relacionar o termo a outra significação referente à posição das mulheres, gerando a base constitutiva de outra memória discursiva.

Tais mobilizações se somam às diversas campanhas e movimentos articulados por diferentes mídias digitais, como, por exemplo, a campanha \#DeixaElaTrabalhar ${ }^{8}$, a qual reivindica um campo profissional igualitário para as mulheres. A referida campanha reuniu um grupo de jornalistas esportivas, via WhatsApp, para organizar relatos de situações de assédio no trabalho. $\mathrm{O}$ movimento ganhou notoriedade e adesão quando lançou um vídeo no YouTube, e outras jornalistas puderam se expressar. Desse modo, entendemos que há um entrecruzamento de discursos que tem tornado o futebol, e o mundo esportivo, em geral maior e mais diversificado ${ }^{9}$. É nesse ínterim que têm emergido discussões a respeito de sub-representatividades de grupos minoritários no mundo esportivo. 
Diante do exposto, lançamos a seguinte questão: como as produções discursivas, tal como a série "Joga que nem mulher", têm oportunizado rearranjos das posições de mulheres nos esportes? Metodologicamente, trata-se de um artigo que problematiza os modos como a produção discursiva enunciada na série "Joga que nem mulher" oportuniza rearranjos das posições das mulheres nos esportes. Nosso argumento é que "Joga que nem mulher" opera como memória discursiva, contrapondo-se à expressão "Joga que nem homem”, flexibilizando a ação de jogar e sinalizando que jogar também é atividade das mulheres.

Nesse sentido, utilizamos o conceito de gênero como categoria analítica, em consonância com Meyer ${ }^{10}$, pensando-o como uma construção social, cultural, linguística, dialógica, entrelaçada aos enunciados que posicionam mulheres e homens, diferenciando-os, distinguindo-os e separando-os. Por essa razão, optamos ao longo da escrita pela expressão "mulheres", no plural, para pensarmos nas diferentes interseccionalidades cunhadas nessa nomeação, a qual as diferencia a partir da raça, classe social, geração, etnia, religiosidade, escolarização, sexualidade, entre outros aspectos.

\section{ANÁLISE DISCURSIVA: COMPOSIÇÕES ANALÍTICAS}

Foucault ${ }^{11}$ define discurso como o conjunto de enunciados que provém de um sistema de formação. Foucault ${ }^{12}$ trabalha com a noção de sistema ao investigar um conjunto de enunciados que podem ser associados a um mesmo, que denominou formação discursiva. $\mathrm{O}$ discurso seria um conjunto de enunciados ligados a uma formação discursiva; assim sendo, as palavras adquirem sentidos diferentes em diferentes formações discursivas.

Estas formações não se fecham, dado seu caráter histórico e, portanto, temporal. Entretanto, Foucault ${ }^{13}$ destaca que é possível analisá-las a partir de sua confrontação com outros agrupamentos discursivos que cercam os enunciados. Desse modo, tomamos esses enunciados como rastros discursivos que manifestam sentidos de épocas diferentes, os quais indicam, em parte, os processos de significação histórica do passado ao presente sobre a posição que as mulheres têm ocupado nos esportes. Isso porque consideramos que "um texto [e, neste caso, incluímos os ditos sobre as mulheres nos esportes] não é um conjunto de signos inertes, mas é o rastro deixado por um discurso em que os enunciados são encenados" ${ }^{14}$. Por essa via, podemos afirmar que essa validação ocorre, segundo Maingueneau ${ }^{15}$, porque se lança mão de recursos linguísticos de "cenas já instaladas na memória coletiva”, empreendendo um diagnóstico do presente.

Portanto, defendemos que a linguagem discursiva é produtiva; ela não apenas enuncia, como produz enquanto enuncia ${ }^{16}$. Em tal perspectiva, Foucault nos ensina a compreender a natureza produtiva do discurso, indicando que "não há saber sem uma prática discursiva, já que toda prática discursiva se define pelo saber que ela forma"17, que ela enuncia. Isso significa que os saberes acionam tecnologias de subjetivação, as quais produzem posições de sujeitos.
10. MEYER, Dagmar Estermann. A politização contemporânea da maternidade: construindo um argumento. Gênero, Niterói, v. 6, n. 1, p. 81-104, 2005 Disponível em: http://www. revistagenero.uff.br/index. php/revistagenero/article/ view/198/134. Acesso em: $15 \mathrm{dez} .2018$.

11. FOUCAULT, 1996.

12. Ibidem.

$13 \mathrm{lbidem}$.

14. MAINGUENEAU, Dominique. Análise de tex tos de comunicação. 6a. ed. São Paulo: Cortez, 2013.

15. Ibidem, p. 85. 16. FOUCAULT, 1996 17. Ibidem, p. 205. 
Nesse sentido, há enunciados, relações e posições que os próprios discursos põem em funcionamento. Dessa forma, analisar o discurso é dar conta exatamente disto: de relações e de práticas concretas que estão "vivas" nos discursos. Ademais, os discursos são constituídos pelos atos de linguagem que enunciam. Os enunciados não são as palavras, frases ou proposições, mas formações que se destacam de corpora discursivos, produzindo a existência e o acúmulo de uma memória de ditos.

Assim, compreender o estado de atualidade dos enunciados, como ensina Foucault $^{18}$, não é só ver o que é sucessivo e histórico, mas o simultâneo, que também o é. As temporalidades discursivas coexistem e possibilitam que o pesquisador identifique as condições e os processos de rearranjos em vias do que pode vir a acontecer.

Metodologicamente, para a realização das análises, pautamo-nos na análise do discurso foucaultiana. Compreendemos que as produções culturais e comunicacionais se sustentam em uma produção discursiva de sentidos que se encontra relacionada à memória. Desse modo, escolhemos a série de reportagens "Joga que nem mulher" por ser de domínio público e seus episódios estarem disponíveis na internet. A opção teórico-metodológica pela análise do discurso implicou o entendimento de que os enunciados carregam marcas e rastros linguísticos, constituintes de uma memória social ${ }^{19}$.

É possível afirmar que a análise do discurso trata das palavras em movimento, buscando compreender a linguagem e seus sentidos, além de trabalhar a relação linguagem/discurso/enunciado, as posições de sujeito e a memória discursiva. É por essa via que operamos com o enunciado reitor da série "Joga que nem mulher" para compormos o corpus de análise. Os enunciados reitores são, para Foucault ${ }^{20}$, como a raiz de uma árvore, ramificações de onde deriva a enunciação; são os enunciados que regem o funcionamento e que desempenham as regras de uma formação discursiva de modo mais concentrado e abrangente, permitindo, desde seu centro linguístico, organizar a emergência de aplicações diversas de outros enunciados.

Os enunciados reitores referem-se à definição das estruturas observáveis e dos campos de objetos possíveis, prescrevem as descrições e os códigos e fazem aparecer as possibilidades mais gerais de caracterização do objeto, abrindo, para outro domínio, novos conceitos a serem construídos ${ }^{21}$. Por sua vez, o enunciado reitor se encontra suscetível aos jogos de força que conduzem a uma memória do presente. É por essa razão que situamos nossa análise na ordem do enunciável, ou seja, inserida em uma perspectiva da materialidade discursiva, linguística e histórica.

Além disso, aventuramo-nos por entre a discursividade do enunciado rei-

18. FOUCAULT, Michel. Governo de si e dos outros: curso no Collège de France (1982-1983). São Paulo: Martins Fontes, 2010

19. Ibidem.

20. FOUCAULT, 2008.

21. Ibidem or, do que é enunciável, a partir de algumas premissas históricas, quanto ao constante movimento dos sentidos, em que, sobretudo, o velho se articula com o novo. Os enunciados analisados emergem da série "Joga que nem mulher" do Globo Esporte, produzida pela RBS TV (RS). O Globo Esporte é um programa da Rede Globo de Televisão exibido de forma ininterrupta desde 1978 
e configura-se como um programa esportivo tradicional, que caracterizamos como um jornalismo esportivo de comunicação de massa. Esse programa é regionalizado; por isso, cada Estado produz suas pautas, tendo 30 minutos de duração. Exibido entre 12h50 e 13h20, o futebol masculino regional, nacional e internacional é um dos carros-chefes das pautas de sua programação.

Para a composição do corpus analítico do presente artigo, selecionamos a série "Joga que nem mulher", exibida em 2017 e composta por quatro episódios. A duração dos episódios variou entre 6 e 10 minutos. Entendemos essa série como especial pelo fato de termos observado o espraiamento desse enunciado em diferentes mídias digitais, como no jornal Zero Hora, na constituição de hashtags, como a \#JogaQueNemMulher, nas mídias digitais, entre outras manifestações em programas de rádio etc. A esse respeito, Covaleski ${ }^{22}$ destaca que há em curso uma nova linguagem dos meios de comunicação contemporâneos, que, por vezes, exploram o conteúdo, transformando-se em redes transmidiáticas.

Essa difusão transmidiática é possibilitada pela movimentação do enunciado "Joga que nem mulher" da mídia tradicional - a televisão - para as mídias digitais. O trânsito comunicacional proporciona uma ampliação discursiva e imagética do enunciado reitor para esses outros espaços. Essa ampliação de sentidos e difusão se materializa por meio de postagens - de imagens e vídeos - com a utilização de hashtags (\#JogaQueNemMulher, \#FutebolFeminino, \#FutsalFeminino, \#JogueComoUmaGarota, \#SoccerGirls) nas redes sociais digitais, como Instagram, Twitter e Facebook. A consolidação de uma difusão transmidiática está vinculada de maneira expressiva na TV e no Instagram. Isso porque, das mídias digitais, o Instagram é a que contempla maior publicização, com 2.156 postagens até o dia 5 de dezembro de 2019; já o Twitter apresenta 287 tweets e o Facebook, 19 postagens; todas essas com a utilização da hashtag \#JogaQueNemMulher.

O compilado das 2.562 postagens representa uma estratégia diferente para a visibilidade das mulheres no esporte. Por ser uma produção local, a série "Joga que nem mulher" criou elementos de mobilização para o seu público. As imagens que utilizam a hashtag \#JogaQueNemMulher formam uma galeria de fotos de times femininos do Rio Grande do Sul. Ao publicizar suas diferentes experiências esportivas em redes sociais, as mulheres se unem a outras que mantêm a mesma relação com o esporte. A conectividade entre as mídias, tradicional e digital, aciona uma ação de visibilidade das mulheres praticantes de esportes. De modo igual, outro veículo comunicacional tradicional, o jornal Zero Hora, produz colunas e viabiliza espaços de reflexão e debate a partir das inúmeras relações entre os esportes, as mulheres e as mídias.

Nessa linha analítica, assistimos inúmeras vezes aos quatro episódios da série "Joga que nem mulher" e realizamos uma leitura dos enunciados que se desdobraram na série; por fim, analisamos as possíveis relações desse enunciado reitor. Em todos os episódios, foi reiterado o que constitui "uma espécie de poder produtivo, o poder de produzir - demarcar, fazer, circular, diferenciar - os corpos" ${ }^{\prime 2}$ das mulheres como corpos que jogam. Dessa maneira, a
22. COVALESKI, Rogério. Publicidade híbrida. Curitiba: Maxi, 2010

23. BUTLER, Judith. Corpos que pesam: sobre os limites discursivos do "sexo". In: LOURO, Guacira Lopes (org.). O corpo educado: pedagogias da sexualidade. 2a. ed. Belo Horizonte: Autêntica, 2001. 
noção de enunciado reitor implicou a análise das condições de sua reiteração, concebendo-o como uma produção histórica, social e, sobretudo, política. A esse respeito, convém esclarecermos que concebemos a política em torno da performatividade nos âmbitos da linguagem, do corpo e da reivindicação dos direitos das mulheres que jogam.

Prosseguindo a discussão, na próxima seção, apresentaremos as análises realizadas a partir do enunciado reitor "Joga que nem mulher", o qual produz enunciados, possibilitando conduções de sentidos e significados em relação ao que se entende sobre a prática das mulheres nos esportes. Destacamos que, no século XXI, as mídias digitais têm impactado os sujeitos, gerando novas subjetividades. As formas atuais de comunicação têm operado a partir de múltiplas conexões que se ramificam tanto em enunciados conservadores quanto em enunciados resistentes. Entre os múltiplos efeitos dessas composições, ressaltamos o rearranjo das fronteiras tradicionais de gênero.

\section{O ARGUMENTO DE QUE JOGAR É "COISA DE HOMEM E DE MULHER"}

Analisamos o enunciado reitor "Joga que nem mulher" na particularidade das marcas linguísticas, na direção de discutir as formulações utilizadas para construir a posição discursiva das mulheres esportistas. Observamos que há algumas estratégias que se alternam nesse enunciado reitor no sentido da afirmação "as mulheres jogam". O enunciado "Joga que nem mulher" é formulado por um verbo de ação em sua forma propositiva - "Joga" -; mais à frente, destaca o sujeito que realiza a ação - a mulher. Compreendemos essa enunciação como uma memória de combate ${ }^{24}$, um contraponto à clássica expressão "Joga que nem homem". Por essa razão, esse enunciado opera como parâmetro flexibilizador e questionador de certa memória social, cultural e discursiva enraizada no Brasil de que futebol é uma atividade viril, exercida

24. FOUCAULT, 2010

25. JOGA que nem mulher - Futebol feminino - Série Globo Esporte. [S. I.]: [s. n.], 2017. Publicado pelo cana Ampliando a Visão. Disponível em: https://www. youtube. $\mathrm{com} /$ watch? $\mathrm{v}=$ qLbatO zS78. Acesso em: 10 mar. 2019.

26. DAMO, Arlei Sander Do dom à profissionalização: uma etnografia do futebol de espetáculo a partir da formação de jogadores no Brasil e na França. 2005. Tese (Doutorado em Antropologia Social) - Universidade Federal do Rio Grande do Sul, Porto Alegre, 2005. apenas por homens.

No que diz respeito à série que constitui nosso corpus de análise, destacamos que ela foi ao ar no ano de 2017, logo após a derrota da seleção masculina de futebol nas Olimpíadas do Rio de 2016 e, ao mesmo tempo, do bom desempenho da seleção feminina de futebol. Esse fato talvez tenha ajudado os telespectadores a "olharem com mais carinho para o que a mulherada anda fazendo pelos gramados" 25 . Olhar com mais carinho" parece colocar em xeque dois elementos: o primeiro, que ninguém esperava um bom desempenho da seleção feminina, e sim da masculina; e o segundo, a relação de sucesso entre "homens e futebol" e de fracasso entre "mulheres e futebol". Nesse sentido, Damo ressalta que os meninos jogam futebol no Brasil "para se fazerem meninos", já que "o futebol é marcado por um arbitrário cultural que o define como um espaço privilegiado da homossociabilidade masculina e de certo modelo de masculinidade" ${ }^{26}$. 
A surpresa de sucesso da seleção feminina de futebol é vista por nós como uma memória de combate, conforme proferido por Foucault ${ }^{27}$, a qual produz um movimento de desestabilização das posições. Ratificando este argumento, Welzer$\operatorname{Lang}^{28}$ afirma que a produção de masculinidades passa pela inserção de meninos em ambientes dados como masculinos, uma vez que o jogo e o campo de futebol seriam espaços deles. $\mathrm{O}$ autor declara que "os homens que não mostram sinais redundantes de virilidade são associados às mulheres e/ou seus equivalentes simbólicos"29. Enunciados como "mulherzinha", "chuta como a mãe" e "mãezinha" eram (e ainda são) geralmente utilizados como chacotas no meio esportivo, o que demonstra a estigmatização da posição das mulheres nos esportes.

A esse respeito, Goellner destaca que os "argumentos sobre os quais repousavam os cuidados com a prática do futebol pelas mulheres recaem, na maioria das vezes, na justificativa de que esse é um esporte que, além de ser considerado violento, requer um nível apurado de preparação física e técnica"30, demarcando que as mulheres são inferiores aos homens nesses quesitos. Essas situações inscrevem a posição de que mulher que joga futebol seria masculinizada. Dessa maneira, as mulheres recebem apelidos e os homens que não se associam ao estilo "masculino de jogar futebol" também sofrem discriminações, sendo, por vezes, intitulados de maricas, fracotes ou mulherzinhas. A exaltação dessas posições de jogar na cultura brasileira esteve sempre associada à produção de um padrão de masculinidade, o qual permitiu, por muito tempo, não só que o futebol fosse visto como específico para a sociabilidade dos homens, mas também que se pensasse que quem não joga bem joga como uma mulher.

Portanto, o enunciado reitor "Joga que nem mulher" indica que a mulher joga, sim, o que se produz pelo cruzamento de outras posições de sujeitos ${ }^{31}$. A partir dessas posições, instalam-se sentidos que se contrapõem, dando uma referência que qualifica as mulheres a ocuparem um lugar referencial. Esse enunciado reitor é uma forma política de constituição de outra posição social para a mulher - ela joga futebol -, a qual filia as mulheres a outras memórias discursivas.

Nesse contexto, ressaltamos também um processo de designação e de referenciação que qual ocorre na formulação do enunciado "Joga que nem mulher", com base em uma relação de evidência entre uma ação e sua referência. Como lembra Foucault ${ }^{32}$, não há discurso sem o processo de deriva de sentidos, sem designação e sem referenciação. A esse respeito, o filósofo faz uma distinção entre designação e referenciação; esses termos, muitas vezes, são usados como sinônimos. $\mathrm{O}$ autor esclarece que designação é o funcionamento semântico pelo qual algo recebe um nome; já a referenciação é vista como a particularização de algo na e pela enunciação.

Desse ponto de vista, entendemos que as enunciações são utilizadas como estratégia na convocação e na reivindicação, mediante um duplo mecanismo linguístico que, ao mesmo tempo que enuncia o jogo como ação de homens, enuncia o jogo como ação das mulheres ao destacar, por exemplo, no segundo episódio da série, os treinos das meninas Giulia e Carol em centros masculinos.
27. FOUCAULT, 2010

28. WELZER-LANG, Daniel. A construção do masculino: dominação das mulheres e homofobia. Revista Estudos Feministas, Florianópolis, v. 9, n. 2 p. 460-482, 2001. Disponível em: http://www.scielo. $\mathrm{br} / \mathrm{pdf} / \mathrm{ref} / \mathrm{v} 9 \mathrm{n} 2 / 8635 . \mathrm{pdf}$ Acesso em: 14 dez. 2018.

29. Ibidem, p. 465.

30. GOELLNER, Silvana Vilodre. Pode a muTher praticar futebol? In CARRANO, Paulo Cesar (org.). Futebol: paixão e política. Rio de Janeiro: DP\&A 2000. p. 79-94.

31. FOUCAULT, 2010. 32. FOUCAULT, 2008. 
33. JOGA que nem muIher..., 2017.

34. FOUCAULT, 2010, p. 11.

35. Ibidem, p. 11.

36. Ibidem, p. 11.

37. JOGA que nem mu-

Iher..., 2017.

38. Ibidem

39. FOUCAULT, 2008

40. BUTLER, Judith. Corpos em aliança e a política das ruas: notas sobre uma teoria performativa de assembleia. São Paulo: Civilização Brasileira, 2018

41. Ibidem, p. 35

42. BUTLER, Judith. O que é a crítica? um ensaio sobre a virtude de Foucault. Cadernos de Ética e Filosofia Política, São Paulo, n. 22, p. 159-178, 2013. Disponível em: https://goo.gl/9flQs9. Acesso em: XX mai. 2017.

43. FOUCAULT, 2008

44. Ibidem
As afirmações que abrem o terceiro episódio apontam: "Somos mutantes, mulheres em transição. Essas meninas são diferentes. Têm a coragem de começar um processo de mudança jogando, vencendo as barreiras. Como tudo, as mudanças estão em curso, elas pagam o preço disso, elas se organizam e jogam"33. Em vista dessas afirmações, entendemos que a série salienta "uma outra memória" ${ }^{4}$, uma posição de que as mulheres jogam. Conforme Foucault, é "a estruturação discursiva que constitui a materialidade de uma certa memória social" 35 , o que implica que "a memória composta pelo discurso é sempre reconstruída na enunciação"36.

O terceiro episódio da série "Joga que nem mulher" destaca movimentos da Confederação Brasileira de Futebol (CBF) para as mulheres se tornarem jogadoras profissionais, remetendo à exigência de times femininos para clubes da Confederação Sul-Americana de Futebol (Conmebol). Assinalam-se também "os investimentos em projetos de nível municipal, regional e estadual que possibilitam a prática do futebol feminino" ${ }^{37}$, embora se ressalte igualmente que estão "longe do sucesso e da visibilidade que o futebol masculino tem" ${ }^{38}$. A série ainda mostra que a inserção das mulheres no futebol ocorre pelas bordas, mas com avanços.

Nesse sentido, consideramos importante frisar que Foucault ${ }^{39}$ propõe que pensemos as formações discursivas como fronteiras que se deslocam e cujo movimento de formulação possui, em seu domínio, outras formulações em relação às quais se produzem certos efeitos de memória. Em outras palavras, a memória discursiva permite, na infinita rede de formulações existente no intradiscurso, o aparecimento, a rejeição ou a transformação de enunciados que pertencem a formações discursivas posicionadas historicamente. Dessa forma, o discurso possui significado por sua inscrição e pertencimento a uma dada formação discursiva historicamente constituída. Assim, podemos entender que a própria "incompletude" é condição e característica da linguagem. Os sujeitos, os sentidos e os discursos nunca estão prontos.

Prosseguindo a análise, em seu quarto episódio, a série inicia com o enunciado "Jogar bem é jogar que nem mulher". Entendemos que a enunciação é carregada de força, porque, quando enunciada, traz à tona um fenômeno. Sobre tal questão, Butler $^{40}$ afirma que a enunciação produz existência ao que declara, fazendo com que uma série de acontecimentos discursivos ocorra como consequência, o que a autora caracteriza como performatividade. Dessa maneira, "a performatividade pode ser entendida como um modo de nomear, um poder que a linguagem produz, um poder na sua condição de repetição, adicionando um conjunto de efeitos" ${ }^{\text {41 }}$. A esse respeito, consideramos imprescindível esclarecer algumas aproximações entre teorizações de Butler ${ }^{42}$ e Foucault $^{43}$. A partir de Foucault ${ }^{44}$ nos aproximamos da conceituação de discurso, enquanto conjunto de enunciados que constituem uma determinada formação discursiva. Tal contribuição do filósofo nos possibilita uma problematização das práticas discursivas e das relações de poder que as sustentam, aspecto que nos permite pensarmos em termos relacionais os discursos em suas tensões e conflitos. Por 
outro lado, Butler ${ }^{45}$ toma a linguagem em sua dimensão performativa, indicando a interação entre um "eu" e um "outro", em um jogo em que ambos estão comprometidos, de certo modo, às consequências de suas ações. Para Butler ${ }^{46}$, é nas práticas performativas reiterativas que ocorrem por meio das dimensões simbólicas da linguagem e da cultura, que os corpos se tornam passíveis de serem pensados. Por essa via, Butler ${ }^{47}$ se insere em uma matriz feminista, a qual contribui indefectivelmente com os tensionamentos presentes em nossas análises, contribuindo para que problematizemos o caráter performativo da linguagem.

Isso porque, Butler ${ }^{48}$ afirma que a linguagem é performática, pois, ao enunciar, faz algo existir; ela produz e conduz a existência social. Assim, entendemos o enunciado reitor "Joga que nem mulher" como um ato performativo de inscrição na linguagem, no qual se declara que as mulheres jogam. A performatividade do ato enunciativo torna-se uma performatividade de gênero. Esse enunciado edifica que as mulheres jogam, o que produz outra posição, por meio da qual a mulher ganha um lugar de visibilidade. Desse modo, temos pensado que a enunciação "Joga que nem mulher", disseminada por toda a série, abre para uma possibilidade produtiva de reconstrução de novas posições de gênero nos espaços públicos. Portanto, ao realizarmos tal análise, não buscamos a confirmação ou validação de uma teoria, mas o estabelecimento de uma análise descritiva que nos possibilita evidenciar a potência dos enunciados.

É nessa direção que a série evidencia novas formas de posicionar as mulheres na esfera pública. Nesse contexto, a "performatividade de gênero presume um campo de reconhecimento, maneira de mostrar"49, a qual apresenta a posição das mulheres enquanto jogadoras. Conforme assegura Butler ${ }^{50}$, reconhecer o gênero depende de um modo de apresentação, de condições para sua existência. A matriz de inteligibilidade de gênero, assim, sedimenta-se em certos jogos de linguagem que conferem sentido às posições de sujeito e definem o que é possível.

É por essa razão que tomamos o "Joga que nem mulher" como enunciado reitor, uma vez que são as ações linguísticas que indicam posições para as mulheres. Dessa maneira, as reiterações desse enunciado são necessárias para sustentar a posição, já que ela não existe fora dos atos de fala que a sustentam ${ }^{51}$. Somos, "de alguma forma, seres linguísticos, seres que precisam da linguagem para ser" $"$. Por essa via, entendemos que a linguagem fornece a base de nossas posições, assim como os parâmetros e limites de nossa habilidade de saber, de agir, de ser. Para Butler ${ }^{53}$, a linguagem é o único material que temos disponível para trabalharmos na melhoria de nossas vidas e da vida dos outros.

O sujeito, conforme Butler ${ }^{54}$, é uma estrutura linguística em formação. A subjetividade não é dada, pois o sujeito está envolvido em um processo de devir. A referida autora compreende os processos de subjetivação como sendo marcados por rupturas, desconstruções e desencaixes. É nesse sentido que Butler $^{55}$ nos possibilita entender que a política do performativo representa um papel decisivo na produção subjetiva: quando dizer equivale a fazer, a política tende a se tornar um modo particular de funcionamento determinado pela
45. BUTLER, 2013. 46. BUTLER, 2013. 47. Ibidem.

48. BUTLER, 2018, p. 35.

49. Ibidem.

50. Ibidem

51. BUTLER, Judith. Excitable speech, a politics of the performatives. New York: Routledge, 1997.

52. BUTLER, 1997, p. 1-2.

53. Ibidem.

54. BUTLER, Judith. Quadros de Guerra: quando a vida é passível de luto? Rio de Janeiro: Civilização Brasileira, 2015.

55. Ibidem. 
56. Ibidem

57. CAMPANELLA, Bruno. Celebridade, engajamento humanitário e a formação do capital solidário. Revista FAMECOS, Porto Alegre, v. 21, n. 2, p. 721-741, 2014 Disponível em: http://revistaseletronicas.pucrs.br/ojs/ index.php/revistafamecos/ article/view/15908. Acesso em: 10 dez. 2018.

58. PROGRAMA DAS NACÕES UNIDASPARA ODESENVOLVIMENTO (PNUD). Relatório Nacional de Desenvolvimento Humano Nacional: Movimento é vida: Atividades Físicas e Esportivas para Todas as Pessoas: 2017. Brasília, DF: PNUD, 2017. Disponível em: https://www.br.undp.org/ content/brazil/pt/home/ library/idh/rdhs-brasil/relatorio-nacional-desenvolvimento-humano-2017.html. Acesso em: 26 dez. 2019. ordem do parecer, em que gestos e declarações produzem. Para a autora, o ato de linguagem realiza o funcionamento político do testemunho.

Nessa direção, o funcionamento discursivo da série "Joga que nem mulher" sugere que nele irrompe um acontecimento desestabilizador de um dizer sobre as mulheres e sobre suas posições no esporte. Tal acontecimento desloca, por meio da linguagem, práticas esportivas historicamente sexistas e misóginas. Assim, filiada à forma-sujeito de direito, essa posição indica um processo de desidentificação do sujeito ${ }^{56} \mathrm{com}$ uma formação discursiva machista, confirmando que a prática discursiva sempre ocorre nesse movimento dos sentidos entre estrutura e acontecimento.

Assim, identificamos uma aproximação entre a discussão desenvolvida por Butler e o modo como Foucault problematiza os processos de constituição dos sujeitos, levando em consideração o efeito de historicização, constituído por acontecimentos que desestabilizam esse processo de constituição por meio de um regime de repetibilidade. Por essa via, podemos afirmar que o enunciado "Joga que nem mulher" aciona os sujeitos, no caso, as mulheres, a uma mobilização de memória discursiva com outros sentidos, tal como as mulheres jogam. De fato, é por isso que, na análise do discurso, cabe observar as derivas que produzem outros sentidos no jogo do mesmo e do diferente.

Nessa perspectiva, a mudança na linguagem faz parte de um processo de mudança da lógica. Isso implica alegar que se trata da recriação das relações entre a linguagem e a cultura. Com efeito, usa-se a linguagem incentivando e criando o rearranjo, no caso, da posição que a mulher joga, e esse enunciado atua na desconstrução de um estereótipo de gênero sustentado na memória social que relaciona a mulher como desqualificada para o jogo esportivo.

Nesse cenário, convém destacarmos que o quarto episódio da série de programas analisada, de certo modo, estimula as mulheres a trocarem as bonecas pela bola, as sapatilhas de balé pelas chuteiras, os vestidos pelos calções e a vencerem os preconceitos. Ao mesmo tempo, esse episódio salienta o quanto as meninas jogam, treinam suas habilidades e têm concentração e determinação. O episódio em questão ainda veicula imagens de mães que jogam e levam seus filhos e filhas para os gramados. Entendemos, assim, que a série "Joga que nem mulher" se converte em capital social e cultural, constituindo o que Campanella ${ }^{57}$ nomeia como capital de visibilidade das mulheres no âmbito esportivo. Esse capital de visibilidade outorga valores simbólicos, de maneira concomitante e complementar, tendo em vista a produção de modificações no discurso social.

Quando se observa o contexto de enfrentamento da inserção das mulheres no esporte, é possível reconhecer que as desigualdades geracionais, raciais e étnicas, bem como os aspectos referentes a escolaridade, renda, classe social e região do país em que vivem os sujeitos, diferenciam as mulheres em grupos distintos, imputando-as desafios. Ratificando o argumento, apontamos que os dados apresentados no Relatório de Desenvolvimento Humano Nacional do Brasil ${ }^{58}$ evidenciam desigualdades sociais e de gênero nas atividades físicas e esportivas, com resultados desfavoráveis às mulheres negras, de menor 
escolaridade e menor renda. No ano "de 2010 o Índice de Desenvolvimento Humano Municipal (IDHM) dos brancos foi de 12,6\% superior ao dos negros, e a renda das mulheres era $28 \%$ inferior à dos homens, mesmo obtendo níveis educacionais mais elevados" ${ }^{29}$. Tais desigualdades têm um peso decisivo na distribuição da prática de atividades físicas e esportivas da população brasileira. Portanto, ratificamos a importância da proposição de políticas públicas de enfrentamento às desigualdades de gênero que contem com a participação efetiva das mulheres.

\section{CONSIDERAÇÕES FINAIS}

No artigo, abordamos a hipótese de que as esferas das mídias digitais em torno de posições enunciativas, como "Joga que nem mulher", são provocativas para a construção de outras memórias discursivas. Entendemos que tais enunciações funcionam como novo ciclo político que desempenha a função de democratização do acesso à inserção, circulação e recepção do debate a respeito das mulheres nos esportes. Mesmo que seja uma mudança lenta, argumentamos que se trata de uma emergência enunciativa, uma vez que desencadeia outras posições de sujeito e a restituição do lugar da mulher que joga.

Essa mudança na esfera da linguagem faz parte de um processo de tensionamento das posições assumidas pelas mulheres na sociedade. De fato, compreendemos que a linguagem como materialidade discursiva acaba por ter a função de uma estrutura que articula e guarda em si espaços de sentidos, os quais se produzem pelo encontro da linguagem, dos corpos e da reivindicação dos direitos. Em tal perspectiva, inferimos que concerne a uma política performativa, a qual, por meio da reivindicação, demanda o reconhecimento das mulheres. Em suma, consideramos que é uma política da performatividade que ratifica uma possibilidade política de transgressão e conquista de direitos, já que o gênero e, mais especificamente, a linguagem são constituídos em planos sociopolíticos de inteligibilidades ${ }^{60}$.

A esse respeito, Foucault ${ }^{61}$ defende que, mesmo na ausência de um interlocutor, a linguagem se dirige sempre a alguém e integra o produto da interação entre locutor e ouvinte. Pela linguagem, o sujeito se constrói, o que pode ser entendido como a construção de uma posição em relação à coletividade da qual é parte. Ora, o social é o mecanismo que move a linguagem e estrutura as enunciações. A enunciação é socialmente dirigida e, em uma formação social, vinculada a filiações de memórias.

Por esse caminho, durante as análises apresentadas, compartilhamos uma discussão sobre as relações entre linguagem e memória, destacando as tramas dos discursos/enunciados. Mostramos que o enunciado "Joga que nem mulher" produz deslizamentos que tornam possíveis movimentos, memórias e outros dizeres. Esse enunciado incentiva a participação das mulheres nos esportes e retoma a memória acerca dos lugares ocupados por elas no universo esportivo. Isso significa que a série "Joga quem nem mulher" edifica a participação das 
mulheres nos esportes, produzindo novos efeitos de sentido, a fim de mostrar que o "jogo" e os espaços esportivos também são lugares a serem ocupados pelas mulheres.

Por fim, cabe ressaltamos que o enunciado reitor "Joga que nem mulher" nos ajuda a compreender que os sentidos das palavras não são fixos e tampouco imanentes. Os sentidos são produzidos em face dos lugares ocupados pelos sujeitos; por isso, joguem, mulheres! Abram espaços para melhores condições de participação, para que haja novos e diversos arranjos, em um viés mais igualitário. O caminho de superação do discurso estereotipado começa pela mudança da linguagem, pelo espraiamento de enunciados que visem à igualdade de participação, pelo reconhecimento e pela proposição de políticas públicas educacionais, assim como de ações afirmativas que promovam uma vida paritária a todos os indivíduos, independentemente do gênero.

\section{REFERÊNCIAS BIBLIOGRÁFICAS}

A copa do mundo de futebol masculino de 2018 foi das mulheres. Zero Hora, Porto Alegre, 18 jul. 2018, p. 22-23.

BUTLER, Judith. Excitable speech, a politics of the performatives. New York: Routledge, 1997.

BUTLER, Judith. Corpos que pesam: sobre os limites discursivos do "sexo". In: LOURO, Guacira Lopes (org.). O corpo educado: pedagogias da sexualidade. 2a. ed. Belo Horizonte: Autêntica, 2001.p. 153-172.

BUTLER, Judith. O que é a crítica? um ensaio sobre a virtude de Foucault. Cadernos de Ética e Filosofia Política, São Paulo, n. 22, p. 159-178, 2013. Disponível em: https://goo.gl/9fIQs9. Acesso em: 10 mai. 2017.

BUTLER, Judith. Quadros de Guerra: quando a vida é passível de luto? Rio de Janeiro: Civilização Brasileira, 2015.

BUTLER, Judith. Corpos em aliança e a política das ruas: notas sobre uma teoria performativa de assembleia. São Paulo: Civilização Brasileira, 2018.

CAMPANELLA, Bruno. Celebridade, engajamento humanitário e a formação do capital solidário. Revista Famecos, Porto Alegre, v. 21, n. 2, p. 721-741, 2014. Disponível em: http://revistaseletronicas.pucrs.br/ojs/index.php/ revistafamecos/article/view/15908. Acesso em: 10 dez. 2018.

COVALESKI, Rogério. Publicidade híbrida. Curitiba: Maxi, 2010.

DAMO, Arlei Sander. Do dom à profissionalização: uma etnografia do futebol de espetáculo a partir da formação de jogadores no Brasil e na França. 2005. Tese (Doutorado em Antropologia Social) - Universidade Federal do Rio Grande do Sul, Porto Alegre, 2005. 
FOUCAULT, Michel. A ordem do discurso. 5a. ed. São Paulo: Edições Loyola, 1996.

FOUCAULT, Michel. Arqueologia do saber. 7a. ed. Rio de Janeiro: Forense Universitária, 2008.

FOUCAULT, Michel. Governo de si e dos outros: curso no Collège de France (1982-1983). São Paulo: Martins Fontes, 2010.

GOELLNER, Silvana Vilodre. Pode a mulher praticar futebol? In: CARRANO, Paulo Cesar (org.). Futebol: paixão e política. Rio de Janeiro: DP\&A, 2000. p. 79-94.

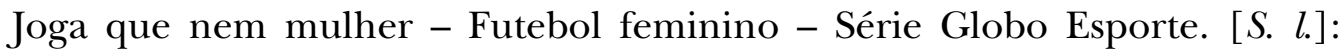
[s. n.], 2017. Publicado pelo canal Ampliando a Visão. Disponível em: https://www.youtube.com/watch?v=qLbatO_zS78. Acesso em: 10 mar. 2019.

MAINGUENEAU, Dominique. Análise de textos de comunicação. 6a. ed. São Paulo: Cortez, 2013.

MEYER, Dagmar Estermann. A politização contemporânea da maternidade: construindo um argumento. Gênero, Niterói, v. 6, n. 1, p. 81-104, 2005. Disponível em: http://www.revistagenero.uff.br/index.php/revistagenero/ article/view/198/134. Acesso em: 15 dez. 2018.

Público feminino é alvo de nova plataforma de conteúdo da ESPN. Portal Imprensa, São Paulo, 2018. Disponível em: http:/ / www.portalimprensa.com. $\mathrm{br} /$ mulheresqueinspiram/materia_21.asp. Acesso em: 10 mar. 2019.

PROGRAMA DAS NAÇÕES UNIDAS PARA O DESENVOLVIMENTO (PNUD). Relatório Nacional de Desenvolvimento Humano Nacional: Movimento é vida: Atividades Físicas e Esportivas para Todas as Pessoas: 2017. Brasília, DF: PNUD, 2017. Disponível em: https://www.br.undp. org/content/brazil/pt/home/library/idh/rdhs-brasil/relatorio-nacionaldesenvolvimento-humano-2017.html. Acesso em: 26 dez. 2019.

WELZER-LANG, Daniel. A construção do masculino: dominação das mulheres e homofobia. Revista Estudos Feministas, Florianópolis, v. 9, n. 2, p. 460-482, 2001. Disponível em: http://www.scielo.br/pdf/ref/v9n2/8635. pdf. Acesso em: 14 dez. 2018. 